\title{
REDES SOCIAIS QUE APOIAM A MULHER DURANTE A AMAMENTAÇÃO
}

Cândida Caniçali Primo1, Pâmela Rodrigues Dutra², Eliane de Fátima Almeida Lima', Sandra Cristina de Alvarenga ${ }^{4}$, Franciele Marabotti Costa Leite ${ }^{5}$

${ }^{1}$ Enfermeira. Doutoranda em Enfermagem. Professora da Universidade Federal do Espírito Santo. Vitória-ES-Brasil. ${ }^{2}$ Enfermeira. Especialista em Neonatologia. Hospital Vila Velha. Vitória-ES-Brasil.

${ }^{3}$ Enfermeira. Doutora em Enfermagem. Professora da Universidade Federal do Espírito Santo. Vitória-ES-Brasil.

${ }^{4}$ Enfermeira. Mestranda em Enfermagem. Hospital Universitário Cassiano Antônio Morais. Vitória-ES-Brasil.

${ }^{5}$ Enfermeira. Doutoranda em Epidemiologia. Professora da Universidade Federal do Espírito Santo. Vitória-ES-Brasil.

RESUMO: Trata-se de uma revisão integrativa da literatura com objetivo de descrever as redes sociais que apoiam a mulher durante a amamentação. A busca ocorreu no mês de Janeiro de 2014 com os critérios de inclusão: artigos em português, inglês e espanhol, publicadas de 2004 a 2013, disponíveis nas bases Literatura Latino-Americana e do Caribe em Ciências da Saúde e Medical Literature Analysis and Retrieval Sistem on-line, a partir dos descritores "condição social, apoio social, aleitamento materno e família". Encontraram-se 23 artigos em Português e três em Inglês. Após a análise definiu-se três categorias: apoio familiar; apoio dos profissionais de saúde e apoio social. Concluiu-se que o companheiro, as avós e as figuras femininas (irmãs, tias), foram os agentes sociais mais citados pelas mulheres. Os profissionais de saúde formam uma rede de apoio importante na continuidade da amamentação.

DESCRITORES: Aleitamento materno; Apoio social; Condição social; Família.

\section{SOCIAL NETWORKS THAT SUPPORT WOMEN DURING BREASTFEEDING}

\begin{abstract}
This was an integrative literature review, with the aim to describe the social networks that support women during breastfeeding. The search took place in January 2014 with the following inclusion criteria: articles written in Portuguese, English and Spanish, published from 2004 to 2013, available on the Latin American and Caribbean Health Sciences Literature and Medical Literature Analysis and Retrieval System on-line databases, using the "social conditions, social support, breastfeeding and family" descriptors. Twenty-three articles in Portuguese and three in English were found. After analysis, three categories were defined: family support; support from health professionals and social support. In conclusion, partners, grandmothers and female figures (sisters, aunts) were the women's most cited social agents. Health professionals form an important support network for continuing breastfeeding.
\end{abstract}

DESCRIPTORS: Breastfeeding; Social support; Social conditions; Family.

\section{REDES SOCIALES QUE APOYAN LA MUJER DURANTE EL AMAMANTAMIENTO}

RESUMEN: Esta es una revisión integrativa de la literatura con objetivo de describir las redes sociales que apoyan la mujer durante el amamantamiento. La búsqueda ocurrió en el mes de enero de 2014 con criterios de inclusión: artículos en portugués, inglés y español, publicados de 2004 a 2013, disponibles en las bases Literatura Latinoamericana y del Caribe en Ciencias de la Salud y Medical Literature Analysis and Retrieval Sistem on-line, por medio de los descriptores "condición social, apoyo social, amamantamiento materno y familia". Fueron encontrados 23 artículos en portugués y tres en inglés. Del análisis, resultaron tres categorías: apoyo familiar; apoyo de los profesionales de salud y apoyo social. Se concluye que el compañero, las abuelas y las figuras femeninas (hermanas, tías) fueron los agentes sociales más citados por las mujeres. Los profesionales de salud forman una red de apoyo importante en la continuidad del amamantamiento. DESCRIPTORES: Amamantamiento materno; Apoyo social; Condición social; Familia.

Universidade Federal do Espírito Santo

Rua João de Oliveira Soares, 241 - 29090-390 - Vitória-ES-Brasil

E-mail: candidaprimo@gmail.com 


\section{INTRODUÇÃO}

Recomenda-se amamentação exclusiva até o sexto mês de vida e que seja complementada até os dois anos ou mais ${ }^{(1)}$. No entanto, menos de $40 \%$ das crianças nos países desenvolvidos são amamentadas exclusivamente até o sexto mês ${ }^{(2)}$. Embora se reconheça todas as vantagens do ato de amamentar ainda verifica-se uma alta taxa de desmame precoce, isso revela que na prática a amamentação não é um ato instintivo ou automático, mas é uma ação que está fundamentada na subjetividade e na vivência das nutrizes, sendo influenciada pela rede social das mesmas $^{(3-5)}$.

A amamentação depende das condições de vida, do trabalho, do momento vivido pela mulher, das experiências anteriores, da trajetória cultural e da compreensão da sociedade e principalmente do apoio da família, da rede social e dos profissionais de saúde ${ }^{(6-7)}$.

Conhecer a rede social na qual a nutriz está incluída é de grande importância para que se possa identificar os indivíduos mais influentes e compreender a interação dessas pessoas com a mulher no processo de amamentar. As principais influências que as mulheres podem sofrer nessa fase são dos familiares, amigos, vizinhos e profissionais de saúde, podendo ser elas positivas ou negativas ${ }^{(8-11)}$.

A nutriz, em meio as transformações ocorridas no puerpério, torna-se sensível às influências externas em relação ao cuidado com a criança e a amamentação ${ }^{(3,6)}$. Os membros da família são os responsáveis pela maior parcela na interferência no processo de amamentação da mulher, sendo as avós, os companheiros e as figuras femininas as mais citadas como apoiadoras nesse processo ${ }^{(11-14)}$. O apoio familiar é considerado essencial para o começo e a continuidade do ato de amamentar ${ }^{(11)}$.

Além disso, o apoio contínuo dos profissionais de saúde por meio do acolhimento nas unidades de saúde, a participação em grupos de apoio, as visitas domiciliares (incluindo os familiares, amigos e vizinhos) durante a amamentação é de suma importância, pois esses são fatores determinantes para uma melhor adesão das mulheres ${ }^{(15-17)}$. Nas relações entre as nutrizes e os profissionais de saúde é possível observar um grau de empatia e cumplicidade e assim, estabelecendo um vínculo de segurança e apoio ${ }^{(11)}$.
Frente a essas questões, o presente estudo tem por objetivo descrever as redes sociais que apoiam a mulher durante a amamentação.

\section{METODOLOGIA}

Trata-se de uma revisão integrativa da literatura, a questão norteadora estabelecida foi: Quais as redes sociais que apoiam a mulher durante a amamentação? A busca na literatura científica ocorreu no mês de Janeiro de 2014 e utilizou os critérios de inclusão: artigos em português, inglês e espanhol, publicadas de 2004 a 2013, disponíveis nas bases de dados Literatura Latino-Americana e do Caribe em Ciências da Saúde (LILACS), Medical Literature Analysis and Retrieval Sistem on-line (MEDLINE). E os critérios de exclusão: editoriais; cartas ao editor; monografias; teses e resumos de congresso ou eventos científicos e artigos de revisão de literatura.

Para o levantamento de pesquisa foram utilizados os seguintes Descritores em Ciências da Saúde (DeCS): "condição social", "apoio social", "aleitamento materno" e "família". Devido ao amplo quantitativo de artigos encontrados optou-se por trabalhar com o cruzamento de dois em dois descritores para a seleção dos artigos estudados. As buscas foram realizadas, de forma independente, por duas pesquisadoras. A primeira seleção dos estudos foi feita a partir da análise dos títulos e resumos, e nos casos de dúvidas a leitura dos textos completos das publicações. Vale destacar que, em situações de divergências, as mesmas foram resolvidas através do consenso entre as duas pesquisadoras. Foram encontrados 957 artigos nas duas bases e após leitura dos resumos e aplicação dos critérios de inclusão e exclusão resultou uma amostra de 26 artigos.

\section{RESULTADOS}

Os artigos selecionados estão apesentados no Quadro 1 de acordo com o ano, país, tipo de estudo e base de dados. Verificou-se que dos 26 artigos, 23 foram obtidos na base de dados LILACS e três na base MEDLINE, sendo que $88,46 \%$ são apresentados no idioma Português, 11,53\%\% em Inglês. Quanto aos anos de publicação pode-se considerar que grande parte é recente 
$(65,38 \%)$, visto que foram publicados a partir de 2009, enquanto que apenas $34,62 \%$ dos artigos possuem data de publicação entre 2004 a 2008. A maioria dos estudos $(88,46 \%)$ teve o Brasil como país de publicação e quanto à abordagem metodológica, 61,53\% são qualitativos.
Após a análise dos artigos estudados foram definidas três categorias para serem discutidas: categoria I - apoio familiar (73,07\% dos artigos selecionados); categoria II - apoio dos profissionais de saúde (61,53\% dos artigos) e categoria III apoio social (34,61\% dos artigos).

Quadro 1 - Distribuição dos artigos de acordo com ano, país, tipo de estudo e base de dados. Vitória-ES-Brasil, 2014

\begin{tabular}{|c|c|c|c|}
\hline Ano & País & Tipo de estudo & $\begin{array}{c}\text { Base de } \\
\text { dados }\end{array}$ \\
\hline 2013 & Brasil & Estudo seccional & LILACS \\
\hline 2013 & Brasil & Estudo descritivo, com abordagem qualitativa & LILACS \\
\hline 2013 & Brasil & Estudo descritivo, com a abordagem qualitativa & LILACS \\
\hline 2012 & Brasil & Estudo descritivo, com abordagem qualitativa & LILACS \\
\hline 2011 & Brasil & Estudo descritivo, com abordagem qualitativa & LILACS \\
\hline 2011 & Brasil & Estudo de abordagem qualitativa & LILACS \\
\hline 2011 & Brasil & Estudo descritivo & LILACS \\
\hline 2010 & Brasil & Estudo de investigação não randomizado & LILACS \\
\hline 2010 & Brasil & Estudo qualitativo & LILACS \\
\hline 2010 & Brasil & Estudo de abordagem qualitativa & LILACS \\
\hline 2009 & Brasil & Estudo descritivo exploratório & LILACS \\
\hline 2009 & Brasil & Estudo descritivo com abordagem qualitativa & LILACS \\
\hline 2009 & Brasil & Estudo de abordagem qualitativa & LILACS \\
\hline 2009 & Brasil & Estudo retrospectivo descritivo-exploratório & LILACS \\
\hline 2009 & Brasil & Estudo descritivo, exploratório e qualitativo. & LILACS \\
\hline 2009 & Brasil & Estudo qualitativo & LILACS \\
\hline 2009 & Brasil & Estudo descritivo-qualitativo & LILACS \\
\hline 2008 & Brasil & Estudo de Coorte. & LILACS \\
\hline 2008 & Brasil & Estudo qualitativo exploratório & LILACS \\
\hline 2005 & Brasil & Estudo qualitativo & LILACS \\
\hline 2005 & Brasil & Estudo quanti-qualitativo & LILACS \\
\hline 2005 & França & Ensaio clínico prospectivo & MEDLINE \\
\hline 2005 & Escócia & Estudo Longitudinal & MEDLINE \\
\hline 2004 & Brasil & Estudo de abordagem qualitativa & LILACS \\
\hline 2004 & Holanda & Ensaio clínico prospectivo & MEDLINE \\
\hline 2004 & Brasil & Estudo descritivo com abordagem qualitativa & LILACS \\
\hline
\end{tabular}

\section{DISCUSSÃO}

\section{Categoria I - Apoio familiar}

Nessa categoria estão incluídos todos os familiares da mulher que deram apoio durante todo o processo de amamentação e cuidados com o bebê. Verificou-se principalmente o apoio do companheiro, da mãe da puérpera e familiares do sexo feminino.
A presença dos familiares é considerada de extrema importância para as mulheres que estão vivenciando o processo de amamentação, pois isso demonstra um ato de carinho e fornece ajuda a essa nutriz. Esse apoio faz com que a mulher se sinta mais segura e confiante para amamentar seu filho ${ }^{(18-21)}$. Um maior apoio familiar está associado a uma maior chance de aleitamento materno exclusivo por um período mais prolongado ${ }^{(7)}$.

A figura feminina é citada como o principal 
grupo que apoia e auxilia a mãe na amamentação, principalmente as mais velhas que por um período de suas vidas também tiveram essa experiência ${ }^{(3,19,22)}$. As avós, tias, irmãs são as mais citadas nos estudos ${ }^{(3,13,18-19,23)}$.

As avós maternas são consideradas uma das peças principais para apoiar a puérpera no período de amamentação. Algumas também trazem a importância do leite materno como um dos principais motivos para suas filhas e noras amamentarem: protege a criança, promove o vínculo afetivo com a mãe, auxilia no desenvolvimento do bebê $\hat{e}^{(13)}$.

A amamentação foi citada pelas mulheres da família como um processo muito importante devido a vários benefícios trazidos tanto para o bebê quanto para a mãe, como por exemplo: é uma fonte para prevenir doenças, ajuda na dentição do bebê, diminui os riscos da mulher desenvolver o câncer de mama ${ }^{(3)}$.

Entre as mulheres que mais necessitam de apoio, vale destacar, que as mães adolescentes precisam de muito suporte, porque elas são facilmente influenciadas por pessoas mais velhas que amamentaram ou não e que também, acabam transmitindo vários tabus e mitos de suas épocas, como por exemplo, o leite é "fraco", não sustenta o bebê, levando ao desmame precoce. Nesse sentido, as adolescentes consideram: o incentivo, a insistência, os conselhos, as informações corretas e o apoio familiar fundamentais para conseguirem amamentar ${ }^{(16-17)}$.

Os companheiros das puérperas são considerados indispensáveis ${ }^{(4,6,24)}$. As mulheres relatam que com a participação deles a amamentação passa ser mais prazerosa, principalmente quando eles sentam ao lado delas nesse momento tão especial ${ }^{(4)}$.

Observou-se que os pais que foram amamentados na sua infância apoiaram mais suas esposas a amamentarem seus filhos, pois conheciam suas vantagens. Os que não foram amamentados ou nunca conversaram com a família sobre o assunto, os seus filhos tiveram a amamentação interrompida precocemente ${ }^{(6)}$. Uma vez iniciada a amamentação é importante que os pais estabeleçam o apoio verbal e elogios à mulher, para assegurar uma amamentação positiva $^{(24)}$.

O envolvimento do marido dando atenção, carinho, afeto, alegria para a mulher é essencial no processo de amamentação. Além disso, muito se acredita que esse cuidado do pai também esteja relacionado a valorização da igualdade de gênero, ter uma relação harmoniosa com sua companheira e ser parte de um sistema econômico que o permita sustentar a família ${ }^{(25)}$.

As nutrizes relacionam muito o apoio familiar não só no ato de amamentar, mas também na ajuda dos afazeres domésticos, no cuidado com o bebê, com os outros filhos, no suporte material e financeiro, e no apoio emocional ${ }^{(5,10,12,15)}$. Algumas atividades que as mulheres citaram que necessitam de ajuda foram: arrumar a casa, dar banho nas crianças, cuidar do umbigo do bebê, lavar roupas e fazer comida. Além disso, relataram a importância de um familiar nos momentos difíceis de aleitar, como: no aparecimento de fissuras, traumas mamilares, mastite e ingurgitamento mamário( ${ }^{(5)}$.

As mulheres relatam que a prática de amamentação muitas vezes envolve: insegurança, angústia, ansiedade, cansaço, preocupação, principalmente pelos múltiplos papéis exercidos por elas. Algumas puérperas desistiram de amamentar porque precisavam voltar ao trabalho, outras por falta de apoio dos seus familiares, algumas se sentiam irritadas e até incomodadas na hora de amamentar e não sabiam explicar o porquê desse sentimento ${ }^{(5)}$.

Estudo aponta que a mulher em processo de amamentação precisa do apoio familiar, mas isso não é determinante, pois verificou que $87 \%$ das mães apoiadas pela família tiveram alta em aleitamento materno exclusivo, enquanto $75 \%$ não tiveram apoio e também saíram em aleitamento materno exclusivo, destarte, significa que o processo de amamentar para a mulher requer muito mais do que apenas apoio familiar ${ }^{(14)}$.

\section{Categoria II: Apoio dos profissionais de saúde}

Os profissionais de saúde foram muito citados como apoio a mulher no processo de amamentação, sendo os mais referenciados: médicos, enfermeiros e agentes de saúde.

Os grupos de gestantes realizados nas unidades de saúde foram muito bem aceitos pelas puérperas, pois nos momentos do grupo recebiam dos profissionais orientações sobre a 
amamentação, esclareciam dúvidas e sentiam-se tranquilas, apoiadas e animadas durantes esses encontros $^{(4,26)}$.

Os grupos de apoio incentivam as nutrizes a amamentar e contribuem para a diminuição do desmame precoce ${ }^{(11,27,20)}$. Um estudo realizado em São Paulo revelou que as mulheres que não participavam do programa de incentivo a amamentação tiveram uma maior ocorrência de desmame precoce do que as que participaram ${ }^{(27)}$. Outra pesquisa também realizada em São Paulo mostrou a importância de um grupo de apoio à amamentação criado na comunidade pelos moradores e profissionais da unidade de saúde. As mães referiram que o grupo significou apoio, amizade, companheirismo, acolhimento dos profissionais de saúde e que sem ele muitas iriam abandonar a amamentação nos primeiros dias pós-parto ${ }^{(11)}$.

Em relação às consultas com os médicos, algumas mulheres decidiram amamentar após a primeira consulta, pois referiam não saber amamentar e o profissional ensinou e esclareceu suas dúvidas e assim, sentiram-se capazes $^{(4)}$. As puérperas relataram que o apoio dos profissionais de saúde foi essencial para o início e a manutenção da amamentação ${ }^{(17,28)}$. Além disso, as visitas preventivas aos consultórios são consideradas essenciais pelos médicos para a continuação do apoio a amamentação ${ }^{(29)}$.

As visitas domiciliares feitas pelas enfermeiras e acadêmicas de enfermagem foram reveladas como algo que as mães estavam precisando naquele momento para que pudessem amamentar e o apoio do profissional no período pós-parto além de ajudar no processo de amamentação, também ajudava no seu autocuidado(21).

Os agentes de saúde e enfermeiros segundo as adolescentes foram os principais profissionais que as ajudaram no processo de amamentar. Essas nutrizes relataram ter adquirido vários conhecimentos com esses profissionais, como: benefícios do aleitamento materno para a prevenção de doenças e crescimento e desenvolvimento da criança. Citaram ter adquirido essas informações no pré-natal, nas palestras e nos cartazes expostos na unidade de saúde. Além disso, relataram que sem as consultas de prénatal, as ações educativas e as visitas domiciliares feitas pelas agentes comunitárias a maioria das adolescentes desistiriam de amamentar ${ }^{(18)}$.
Os principais suportes dos profissionais de saúde citados pelas puérperas foram os conselhos, as orientações e informações referentes ao aleitamento materno. As questões mais abordadas pelos profissionais foram aquelas relacionadas aos mitos ("leite materno é fraco") e que o aleitamento materno exclusivo deve ser mantido até os seis meses da criança ${ }^{(12)}$. Algumas relataram a importância do suporte dos profissionais após o parto, as enfermeiras as ajudaram a amamentar, ensinaram a massagear as mamas antes de dar mamar, a pega correta que o bebê deve fazer para não machucar a mama ${ }^{(24)}$.

As principais ações desenvolvidas pelos profissionais foram: a educação em saúde e o auxílio direto no cuidado com o bebê, mediante ajuda para a pega correta nas primeiras mamadas e nas consultas de puericultura ${ }^{(17)}$.

Os primeiros dias de amamentação são de extrema importância para a eficácia da amamentação, pois se constitui de um período de aprendizado para a mãe e o recém-nascido. E, além disso, é nesse momento que os profissionais de saúde, principalmente os agentes comunitários e enfermeiros, precisam apoiar e incentivar a mãe a estabelecer a amamentação devido ao aparecimento das grandes dificuldades para $\mathrm{o}$ seu sucesso ${ }^{(18)}$.

Problemas como fissuras/dor mamilar, ingurgitamento mamário, mamilos planos e invertidos são muito encontrados nos primeiros dias pós-parto e é nesse momento que as puérperas relatam a necessidade do apoio dos profissionais de saúde, que devem orientar e apoiar as nutrizes para que possam vivenciar a amamentação de forma efetiva e tranquila ${ }^{(5,18)}$.

O período puerperal é considerado um momento delicado e requer atenção e cuidados da equipe de saúde ${ }^{(5,22)}$. Algumas mulheres relataram a insensibilidade dos profissionais frente a sua dor durante a amamentação ${ }^{(5)}$ e disseram sentirem-se sozinhas devido a pouca proximidade dos profissionais que as atenderam nos serviços de saúde ${ }^{(19)}$.

Estudos revelam a importância das ações educativas feitas pelas equipes de saúde na vida da mulher que está vivenciando a amamentação. As puérperas relataram que as ações educativas as ajudam guiar, incentivar, ensinar, orientar e esclarecer suas dúvidas sobre amamentação(22,26). Da mesma forma, a sala de aconselhamento na unidade de saúde oportuniza momentos de 
orientação, esclarecimento e apoio ${ }^{(26)}$. Além disso, essas atividades educativas devem ser desenvolvidas nos domicílios, nas escolas, nas unidades de saúde e também pela mídia, as novelas deveriam mostrar a importância da amamentação.

Estudo mostra que uma consulta precoce (duas semanas pós-parto) com médicos da atenção primária aumentou o índice de amamentação e que um programa de formação de curta duração para treinar os médicos pode contribuir para a melhora nos resultados de amamentação(29). Apenas um estudo relatou que um programa para apoio a amamentação não se mostrou eficaz, e verificou que precisava reavaliar as categorias profissionais envolvidas; o número e duração dos contatos, em especial nas primeiras semanas após o parto, e dar mais ênfase no aconselhamento de saúde como prevenção ao invés de dar ênfase nos problemas da amamentação ${ }^{(23)}$.

\section{Categoria III: Apoio Social}

Incluem-se nessa categoria o apoio recebido das pessoas que convivem com a puérpera e que não são familiares, como: amigos, vizinhos, pai da criança que não coabita com ela, colegas de trabalho entre outros.

Algumas mulheres referiram a vizinha como o principal apoio, pois foi a pessoa que a ajudou com o bebê durante a amamentação ${ }^{(19)}$. $\mathrm{O}$ apoio que as puérperas expressam não é apenas no ato de amamentar, foram desveladas algumas razões que levaram a mulher a procurar a ajuda de suas amigas e vizinhas, como por exemplo: o apoio material, auxílio nas tarefas de casa, ajuda para cuidar da criança. Contar com as amigas e vizinhas nessas atividades foram essenciais para que a mulher pudesse amamentar seus filhos em casa durante os primeiros meses pós-parto ${ }^{(7,10)}$.

O suporte dos amigos e vizinhos é fundamental para o estabelecimento e continuação da amamentação, isso faz com que a mulher se sinta mais segura e confiante para cuidar de seu filho ${ }^{(5,8)}$.

Mães de recém-nascidos prematuros se sentem ainda mais inseguras no cuidado com seus bebês e relataram ter sua autoestima baixa nesse momento, com isso o apoio da rede social se torna mais importante para que a mulher não desista de amamentar ${ }^{(8)}$.

As puérperas muitas vezes não possuem familiares por perto e isso faz com que elas busquem ajuda e apoio por meio dos vínculos com amigos e vizinhos. Com isso evidencia-se a importância da rede de suporte social no período pós-parto onde além de ajudar no processo de amamentação, nas técnicas e complicações, também ajuda a mulher com relação aos seus medos, angústias e adaptação no seu novo papel de ser mãe $\mathrm{e}^{(21)}$.

Os conhecimentos e vivências maternas de amigos e vizinhos são repassados como conselhos e exemplos, com discursos ora a favor ora contrário à amamentação. Esses conhecimentos oriundos do senso comum são permeados de mitos e tabus (como: o leite é fraco e não sustenta o seu filho, amamentar deixa a mulher mais fraca), que podem determinar a continuidade ou não da amamentação ${ }^{(22)}$.

O apoio da rede social também é importante na manutenção da saúde mental e enfrentamento das situações estressantes como as fases de transição após o nascimento do bebê. Estudos revelam que um terço das mulheres no período puerperal pode sofrer de depressão pós-parto e isso faz com que a amamentação seja um ato ainda mais difícil. Algumas nutrizes necessitam parar de amamentar devido a tratamentos com medicação incompatível com a amamentação ${ }^{(5)}$.

Observou-se que as puérperas inseridas no mercado de trabalho introduziram outro leite antes dos 6 meses devido a necessidade de retorno às atividades profissionais. Essas mulheres relatam que a sociedade não apoia a mulher que trabalha e amamenta, além disso, sentem-se pressionadas no ambiente profissional pela chefia dificultando assim suas ações para a manutenção da lactação ${ }^{(25)}$.

A religião também foi referida como um apoio nesse período de amamentação, as nutrizes relataram que se sentiam mais pacientes, ajudava no apoio espiritual (uma sensação de leveza). Também, realizavam-se reuniões relacionadas a vários assuntos, incluindo a amamentação, cuidados com o bebê e isso as deixavam mais confiantes e seguras. Algumas referiram que em decorrência da ajuda recebida pela igreja por meio das missionária ocorreu um aumento na sua produção de leite ${ }^{(4)}$. 


\section{CONCLUSÕES}

Como resultado deste estudo, pode-se afirmar que o apoio familiar, social e dos profissionais de saúde é essencial na vida da nutriz durante o processo de amamentação.

O companheiro, as avós e as figuras femininas (irmãs, tias), foram os agentes sociais principais e mais citados.

O apoio familiar e social está relacionado também com a ajuda nos afazeres domésticos, nos cuidados com o bebê, com os outros filhos, no suporte material e financeiro e apoio emocional. As mulheres que não possuem familiares próximos contam com a ajuda principalmente da vizinha nesse momento tão complexo para ela, principalmente pelos vários papéis exercidos nesse período.

Os profissionais de saúde devem apoiar a nutriz principalmente nos primeiros dias e semanas pós-parto, pois é nesse período que as dificuldades aparecem. Os resultados apontam que os profissionais de saúde formam uma rede de apoio importante na continuidade da amamentação, no entanto ainda existem relatos de insensibilidade com a dor e com as dificuldades enfrentadas pelas mulheres refletindo nos índices de amamentação.

\section{REFERÊNCIAS}

1. Organização Mundial da Saúde/UNICEF. Reunião Conjunta OMS/UNICEF sobre alimentação de lactentes e crianças na primeira infância: declaração, recomendações e relação dos participantes. Genebra: UNICEF; 1980.

2. Venancio SI, Escuder MM, Saldiva SR, Giugliani ER. Breastfeeding practice in the Brazilian capital cities and the Federal District: current status and advances. J. Pediatr. 2010;86(4):317-24

3. Barreira SMC, Machado MFAS. Amamentação: compreendendo a influência do familiar. Acta Sci. Health Sci. 2004;26(1):11-20

4. Buchala LM, Moraes MS. Amamentação vivenciada com sucesso por um grupo de mulheres. Arq. Cienc. Saude. [Internet] 2005;12(4) [acesso em 13 jan 2014] Disponível: http://br.monografias.com/ trabalhos-pdf900/amamentacao-vivenciada-mulheres/ amamentacao-vivenciada-mulheres.pdf

5. Fujimori E, Nakamura E, Gomes MM, Jesus LA, Rezende
MA. Aspectos relacionados ao estabelecimento e à manutenção do aleitamento materno exclusivo na perspectiva de mulheres atendidas em uma unidade básica de saúde. Interface. [Internet] 2010;14(33) [acesso em 14 jan 2014]. Disponível: http://dx.doi. org/10.1590/S1414-32832010000200007

6. Pontes CM, Alexandrino AC, Osório MM. O envolvimento paterno no processo da amamentação: propostas de incentivo. Rev. Bras. Saude Mater. Infant. [Internet] 2009;9(4) [acesso em 20 mar 2014]. Disponível: http://dx.doi.org/10.1590/S151938292009000400003

7. Morgado CMC, Werneck GL, Hasselmann $\mathrm{MH}$. Rede e apoio social e práticas alimentares de crianças no quarto mês de vida. Cienc. Saude Colet. 2013;18(2):367-76.

8. Silva LR da, Elles MEIS, Silva MDB, Santos IMM, Souza $\mathrm{KV}$, Carvalho SM. Fatores sociais que influenciam a amamentação de recém-nascidos prematuros: estudo descritivo. Online Braz. J. Nurs. [Internet] 2012;40 [acesso em 29 mar 2014.]. Disponível: http://www. objnursing.uff.br/index.php/nursing/article/view/3528

9. Machado MMT, Bosi MLM. Compreendendo a prática do aleitamento exclusivo: um estudo junto a lactantes usuárias da rede de serviços em Fortaleza, Ceará, Brasil. Rev. Bras. Saude Mater. Infant. [Internet] 2008;8(2) [acesso em 15 jul 2014] Disponível: http:// dx.doi.org/10.1590/S1519-38292008000200006

10. Souza MHN, Souza IEO, Tocantins FR. Abordagem da fenomenologia sociológica na investigação da mulher que amamenta. Rev. Enferm. UERJ. 2009;17(1):52-6

11. Montrone AVG, Fabbro MRC, Bernascone PBS. Grupo de apoio à amamentação com mulheres da comunidade: relato de experiência. Rev. APS. [Internet] 2009;12(3) [acesso em 25 jan 2014] Disponível: http://aps.ufjf.emnuvens.com.br/aps/ article/viewFile/303/235

12. Marques ES, Cotta RMM, Botelho MIV, Franceschini SCC, Araújo RMA, Lopes LL. Rede social: desvendando a teia de relações interpessoais da nutriz. Physis. [Internet] 2010;20(1) [acesso em $23 \mathrm{fev}$ 2014] Disponível: http://dx.doi.org/10.1590/S010373312010000100014

13. Gross FM, Van der Sand ICP, Girardon-Perlini NMO, Cabral FB. Influência das avós na alimentação de lactentes: o que dizem suas filhas e noras. Acta Paul. Enferm. 2011;24(4):534-40.

14. Caetano LC, Nascimento GS, Nascimento MCA. A família e a prática de amamentação em bebês de baixo peso ao nascer. Rev. Eletr. Enf. [Internet] 2011;13(3) [acesso em 26 abr 2014]. Disponível: http://www. revenf.bvs.br/scielo.php?script=sci_arttext\&pid=S151819442011000300008\&lng=pt 
15. Machado ARM, Nakano AMS, Almeida AM, Mamede MV. O lugar da mãe na prática da amamentação de sua filha nutriz: o estar junto. Rev. Bras. Enferm. 2004;57(2):183-7.

16. Takemoto AY, Santos AL, Okubo P, Bercini LO, Marcon SS. Preparo e apoio à mãe adolescente para a prática de amamentação. Cienc. Cuid. Saude. [Internet] 2011;10(3) [acesso em 11 mai 2014]. Disponível: http:// dx.doi.org/10.4025/cienccuidsaude.v10i3.17362

17. Mazza VA, Nunes RCT, Tararthuch RZP, Alexandre AMC, Patel JV. Influência das redes sociais de apoio para nutrizes adolescentes no processo de amamentação. Cogitare enferm. [Internet] 2014;19(2) [acesso em 16 jul 2014]. Disponível: http://dx.doi. org/10.5380/ce.v19i2.36975

18. Nunes JM, Oliveira EN, Vieira NFC. Concepções de puérperas adolescentes sobre o processo de amamentar. Rev. Rene. [Internet] 2009;10(2) [acesso em 26 jan 2014]. Disponível: http://www.revistarene. ufc.br/10.2/html/10_2_9.html

19. Souza MHN, Souza IEO, Tocantins FR. A utilização do referencial metodológico de rede social na assistência de enfermagem a mulheres que amamentam. Rev. Latino-Am. Enferm. [Internet] 2009;17(3) [acesso em 23 jul 2014] Disponível: http://dx.doi.org/10.1590/ S0104-11692009000300012

20. Albernaz E, Araújo CL, Tomasi E, Mintem G, Giugliani E, Matijasevich A, et al. Influência do apoio à amamentação nas tendências das taxas de aleitamento materno da cidade de Pelotas (RS), 1982-2004. J. Pediatr. [Internet] 2008;84(6) [acesso em 15 jan 2014]. Disponível: http://dx.doi.org/10.1590/S002175572008000700015

21. Joca MT, Oliveira RL, Barbosa RCM, Pinheiro AKB. Compreendendo o aleitamento materno através da vivência de nutrizes. Rev. Rene. [Internet] 2005;6(3) [acesso em 25 jul 2014]. Disponível: http://www. repositorio.ufc.br/bitstream/riufc/4533/1/2005_art_ mtjoca.pdf

22. Frota MA, Mamede ALS, Vieira LJES, Albuquerque CM, Martins MC. Práticas culturais sobre aleitamento materno entre famílias cadastradas em um programa de saúde da família. Rev. Esc. Enferm. USP 2009;43(4):895901.

23. Kools EJ, Thijs C, Kester AD, Van den Brandt PA, de Vries $\mathrm{H}$. A breast-feeding promotion and support program a randomized trial in the Netherlands. Am. J. Prev. Med. 2004;40:60-70.

24. Piazzalunga CRC, Lamounier JA. O contexto atual do pai na amamentação: uma abordagem qualitativa. Rev. Med. Minas Gerais. [Internet] 2011;21(2) [acesso em 24 jul 2014].Disponível:http:// www.clinicaventura.com.br/arquivos/ central/3256751cde19b16c0e92a9425ba1fd37.pdf

25. Müller FS, Silva IA. Representações sociais de um grupo de mulheres/nutrizes sobre o apoio à amamentação. Rev. Latino-Am. Enferm. [Internet] 2009;17(5) [acesso em 24 jul 2014]. Disponível: http://dx.doi.org/10.1590/ S0104-11692009000500009

26. Linhares FMP, Pontes CM, Osório MM. Breastfeeding promotion and support strategies based on Paulo Freire's epistemological categories. Rev. Nutr. [Internet] 2013;26(2) [acesso em 23 jun 2014] Disponível: http:// dx.doi.org/10.1590/S1415-52732013000200001

27. Brasileiro AA, Possobon RF, Carrascoza KC, Ambrosano GMB, Moraes ABA. Impacto do incentivo ao aleitamento materno entre mulheres trabalhadoras formais. Cad. Saude Publica. [Internet] 2010;26(9) [acesso em 16 abr 2014]. Disponível: http://dx.doi. org/10.1590/S0102-311X2010000900004

28. Swanson V, Pwer KG. Initiation and continuation of breastfeeding: theory of planned Behaviour. Blackwell Publishing Ltd. 2005;50(3):272-82.

29. Labarere J, Gelbert-Baudino N, Ayral A-S, Duc C, Berchotteau M, Bouchon N, et al. Efficacy of breastfeeding support provided by trained clinicians duringan early, routine, preventive visit: a prospective, randomized, open trial of 226 mother-infant pairs. Pediatrics. 2005;115(2):e139-46. 